\title{
Mediating distance: new interfaces and interaction design techniques to follow and take part in remote museum visits
}

\author{
Galena Pisoni
}

Department of Information Engineering and Computer Science (DISI), University of Trento, Trento, Italy

\begin{abstract}
Purpose - This paper presents a study of a system that allows remote and onsite visitors to share a museum visit together in real time. The remote visitors are older adults at a care home and their relatives and/or friends who are at the museum. The museum visits are interactive. Meaningful stories accompany the museum exhibits, and there's an audio channel between onsite and remote visitors. The aim of the study is to determine whether the remote visitors, i.e. older adults are able to use such technology and to study the mediated sense of spatial presence, social closeness, engagement and enjoyment in the visit. This study discusses the relationship between these aspects and factors leading to a better remote experience for older adults.

Design/methodology/approach - This study has 14 onsite and 12 remote older adult participants. Standardized questionnaires measured the mediated sense of spatial presence, the experienced social closeness and the level of participants' engagement and enjoyment in the visit of the older adult participants and traced onsite visitors in their position during the visit. The audio logs were subjected to thematic content analysis.

Findings - The results show that older adults enjoy and engage in remote visits, and that there is a positive correlation between enjoyment, engagement and social closeness. The findings argue that both the audio channel and the interactive story are important for creating an affective virtual experience: the audio channel increases the sense of closeness, whereas the interactive story makes the visit more engaging, providing structure, direction and purpose to the visit.
\end{abstract}

Originality/value - This work advances the state of art in the domain of technologies for older adults and addresses the needs of this population to stay in contact with both people and places.

Keywords Museums, Older adults, Remote participation

Paper type Research paper

\section{Introduction}

In research on aging, much effort has been devoted to identifying viable alternatives for meetings and interactions for seniors physically separated from their homes, families and friends. Mobility constraints, bereavement, declining social networks or physical relocation are closely associated with poor mental and physical health (Garattini et al., 2012). Restricted

(C) Galena Pisoni. Published by Emerald Publishing Limited. This article is published under the Creative Commons Attribution (CC BY 4.0) licence. Anyone may reproduce, distribute, translate and create derivative works of this article (for both commercial and non-commercial purposes), subject to full attribution to the original publication and authors. The full terms of this licence maybe seen at http://creativecommons.org/licences/by/4.0/legalcode

The authors would like to acknowledge and thank all the older adults who took part in the study and thus made this work possible.

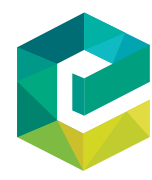

Journal of Systems and Information Technology Vol. 22 No. 4,2020 
JSIT 22,4

physical mobility reduces engagement in social activities and can lead to depression increasing the chance of a decline in health (Zhao et al., 2014). Staying in touch with people is important to older adults for social support. Active participation in social events reduces the risk of depression, anxiety and cognitive impairment (Holtfreter et al., 2017). Engaging in leisure activities has been shown to have a positive effect on the quality of life and general well-being (Yates and Orrell, 2016).

Numerous studies explore how communication technologies can be successfully incorporated into the everyday life of older adults. Information and communications technologies (ICTs) for older adults impose unique challenges because:

- there are asymmetries in the communication needs between older adults and middleaged or younger adults; and

- there are different emotional and cognitive needs and abilities between older adults and middle-aged or younger adults (Hope et al., 2014; Dragojevic et al., 2015; Barbosa Neves et al., 2019).

Different technologies have been adopted by older adults and their family members and they often provide a much better sense of connection than mobile phones.

Cultural heritage sites and museums increasingly use new technologies to connect with visitors in an emotional, participatory, interactive and social fashion, even when the visitors visit the museum virtually (Schall et al., 2018; Perry et al., 2017). Technologies are considered valuable resources for engaging audiences and supporting their conversations. Many visitors come to museums as part of small groups (Falk, 2016), and interaction among visitors may enhance the entire visitor experience (Antón et al., 2018; Skydsgaard et al., 2016). New tools for communication may increase this interaction and hence contribute to the visit. During a visit, groups talk about their experiences in variety of ways: sometimes they talk about trivial things, at other times about shared or individual past experiences, and some are clearly informed by the details of what they see. Previous literature (Skydsgaard et al., 2016) has shown that conversation at the moment of the visit is important as this is the moment when co-construction of meaning happens, and memories are created that can be recalled later.

In this paper we propose a new method that enables older adults to take an active part in a museum visit for a small group via drama (Roussou and Katifori, 2018; Rubino et al., 2015). In this drama-based visit, the remote participant joins the onsite visitors as they walk around the museum with the help of technology, both parties are connected via an audio link, and the information about the objects is presented in the form of a story/drama connecting the objects in the exhibition (Callaway et al., 2014; Rubino et al., 2015). We use this method in situ with the aim of evaluating the suit ability of the technology for remote visitation of museums by older adults. In addition, we look for potential improvements in the overall user experience. Qualitative research methods (observations, semi-structured interviews, and content analysis) together with quantitative research methods (statistical analysis of data gathered from standardised questionnaires) are used as a means to better understand users' perceptions and their willingness to use technology. With this research we aim to answer the following research questions:

$R Q 1$. Is a drama-based visit an enjoyable experience for the older adult?

Our first research question is directed at understanding whether a visit with our drama-based approach is enjoyable and how it affects the other variables. Given the fact that we provide an interactive social visit, we expect participants to enjoy the visit: 
$R Q 2$. Do older adults feel engaged during a drama-based remote visit?

With this question we want to investigate if the participant actively engages in the visit, and shows further interest in the presented content. We expect engagement to take place and to have an effect on the other variables:

RQ3. Do older adults experience spatial presence in a drama-based remote visit?

This question is directed at whether the participant experienced a feeling of "being there". We expect the participants to experience spatial presence:

RQ4. Do remote participants experience social closeness with the rest of the group in a drama-based visit?

Do remote participants feel as if they are part of the onsite group, or do they feel separated because of their physical distance? With this question we want to investigate the ability of our application to create the feeling of "being there with someone", and find out whether they feel they are part of the group:

RQ5. Do the dynamics of the onsite group influence the experience of the remote participant (s)?

Is the remote participant experience correlated with the dynamics of the onsite group? For example, if the group stays closer together or talks more during the visit, does the remote participant enjoy or engage more in the visit? If the visit lasts longer will the remote participant enjoy/engage more? We expect a positive correlation.

The wider goal of the research is to understand: older adults' view on what the proposed remote visiting system means for them and how it may be used; older adults' perceived usefulness and suitability and criteria for older adults to accept and use the system.

To our knowledge, there has been no prior research that specifically tests the use of the drama-based approach for older adults in a remote museum visitation. Previous work focused on other types of approaches for remote museum visitations for older adults (Kostoska et al., 2015; Beer and Takayama, 2011; Kostoska et al., 2016; Pisoni et al., 2019; Díaz-Rodríguez and Pisoni, 2020), and our work advances the state of art by providing an empirical investigation of the appropriateness of the drama-based approach for remote museum visits for older adults. Our work addresses the need of this population to stay in contact with both people and places. We seek additional input as to whether the approach is suitable and whether the system that we have created is indeed fit for purpose. From our experiment, we understand that it was positively received by older adults, and our results suggest potential benefits related to the social and communicative needs of older adults.

We report here on our results to underline the potential of technology like this to help decrease the isolation that older adults experience and how technology like this can be used in a care home. We begin by presenting background work and describing the specific technology we used. We proceed by explaining the research questions of interest, the experimental setup and measures used, and we present the evaluation results. We conclude by discussing the current experimental findings and how our research is situated within the larger discussion about technology for social inclusion of the elderly.

\section{Background}

The potential for ICTs to bridge social and spatial barriers has been examined in several studies (Cotten et al., 2011; Cotton et al., 2012; Winstead et al., 2013). Qualitative

Evaluating older adults' ability 
JSIT 22,4

studies with older adults using technologies like Google Maps with Street View and virtual tours of institutions found that ICTs can provide a means of staying connected with places of sentimental value or to "visit" places of interest that are no longer accessible to them. These online visits resulted in lower levels of loneliness and social isolation. Internet communication technology can help older adults feel as though they are in companionship with others even when they are physically unable to leave their residence (Barbosa Neves et al., 2019).

Technological advances offer "telepresence" or mobile remote presence (MRP) systems as another opportunity for bridging social and spatial barriers for older adults (Vandemeulebroucke et al., 2018). MRPs are designed to be teleoperated and are used to improve communication between individuals. They have the potential to assist older adults in instrumental activities of daily living as well as to foster social interaction between people (Wang et al., 2017). A qualitative study where older adults used an MRP system identified benefits for the participants such as being able to see and to be seen, reducing costs and hassles associated with traveling, and reducing social isolation (Beer and Takayama, 2011). Many of the participants expressed the desire to go outside, visit new places attend live performances and visit museums.

Another way to alleviate mobility disadvantages for older adults is through the use of virtual environments. Virtual environments offer users the ability to navigate in new or known environments and contexts, interacting with people in different locations. Virtual environments can provide a realistic experience, offering the participant's a feeling of "being there" in an environment, also defined as a sense of presence (Aljaroodi et al., 2019). In addition, researchers have distinguished between: spatial presence, which refers to the sense of physically being in another location, forgetting about the technology involved and accepting the virtual environment as a real environment (Wirth, 2007), and social presence, which is generally referred to as "the feeling of being together (and communicating) with someone" (Biocca Harms and Burgoon, 2003). Research has shown that users are more likely to accept virtual environments when the mediated environment is more salient (Decock et al., 2014).

The use of virtual environments in museums is on the rise (D'Alba and Jones, 2013; Roussou and Katifori, 2018). The aim is to increase interest in the museum topics as well as offering seamless exploration from home. When users are emotionally and intellectually engaged in the experience, their engagement increases their sense of presence. Virtual environments hold the promise of achieving physical, sensory, and mental activity and response.

To facilitate the process of engagement and collaboration between peers, narratives or drama are often introduced into the museum contexts (Roussou and Katifori, 2018; Rubino et al., 2015; Katifori et al., 2018).According to Gorini et al. (2011) narratives are responsible for mental immersion through which users are engaged and involved in the experience, to increase their sense of mediated presence. Results have shown that drama, when designed for small groups, and combined with the raw emotion of being in front of actual original artefacts, can emotionally engage visitors (Schall et al., 2018). We build specifically on this previous research to try to make it inclusive for remote older adult visitors too.

The current system is an augmented version of a dramatic audio guide for small groups (Callaway et al., 2014). It includes real-time sensors that monitor position and microphone activity for each individual in the group, allowing us to determine whether they are talking to each other and what exhibits they are looking at, as well as reinforcing a sense of group togetherness by, for example, requiring group members to be physically near each other before a dramatic presentation begins. While a large-scale evaluation is still underway, it 
has proven effective at promoting conversation in groups, especially when compared to groups that use identical hardware but that isolate individuals with separate audio presentations.

We also build on our previous research and on research on social museum experiences for remote visitors (Peters et al., 2016; Ens et al., 2019; Kostoska et al., 2013). Studies with remote participants have shown that social interaction with companion (s) while co-visiting, can directly influence the remote visitor's museum experience. They show that audio interaction, spatial awareness and mutual visibility are essential factors for co-visiting between remote users. Our work advances previous work by specifically investigating how we can use such systems for social inclusion of older adults, and how we can improve remote visits from home by tailoring it for older adults taking into account their special needs.

We additionally attempt to study hybrid social interactions in this scenario, i.e. interactions where face-to-face interaction and mediated interaction occur in the same time and group (Van Dijk et al., 2011). In our case remote person (s) interact with onsite visitor (s) while they visit a museum. In this kind of interaction, the remote participant (s) might, as a consequence of their distance, feel different about the group, and the outcomes of the visit. Our work specifically focuses on studying the remote participant (s) in this scenario, and identifying their potential concerns, benefits and criteria for acceptance of such a system.

\section{Method}

This study was carried out to test the drama-based approach with our target users, older adults in a care home. The goal of the study is to evaluate the general usefulness of the drama-based approach and to answer our specific research questions, i.e. to what extent does it make users engage, enjoy, and feel as if they are there, physically and socially. For this study, we used as a testbed a new museum of the natural sciences in Trento, Italy called MUSE (www.muse.it/en), a museum targeting the topics of evolution, the nearby Dolomite mountains, nature, natural history and biodiversity. For the purposes of this experiment we chose the underground floor of the museum which focuses on the formation of the Earth and evolution. The evaluation with the older adults took place at AziendaFeltrina "A. Brandalise", in Feltre, Italy, an institution $80 \mathrm{~km}$ from the museum. All activities were undertaken in the Italian language.

\subsection{Participants}

We had two types of participants: remote visitor (s) and onsite visitor (s). A summary of the

people involved in the experiment, as well as the selection criteria is shown in Table 1.

\begin{tabular}{|c|c|c|}
\hline \multicolumn{2}{|c|}{ People involved in the experiment } & \\
\hline Remote visitor (s) & Older adult (s), participating from care home & \\
\hline Onsite visitor (s) & Young adult (s), participating from the museum & \\
\hline Research assistant at care home & Introducing the remote visitor (s) to the experiment & \\
\hline Research assistant at museum & Introducing the onsite visitor (s) to the experiment & \\
\hline \multicolumn{3}{|l|}{ Screening criteria for participant (s) } \\
\hline SPMSQ & Below 7 & \\
\hline Severe Physical Disability & No & Table 1. \\
\hline \multicolumn{2}{|l|}{ Screening criteria for onsite visitor (s) } & Parties involved in \\
\hline Place of origin & Same as the care home & the study and their \\
\hline Age & Below 55 & selection criteria \\
\hline
\end{tabular}

\section{Evaluating older adults' ability}

333 
JSIT

22,4

334

Older adult participants who had physical difficulties in moving were selected from a care home far away from the museum. They participated in the experiment with the aid of a research assistant at the care home. The research assistant was responsible for establishing the internet connection with the museum, introducing the participants to the experiment and submitting the questionnaire at the end of the study.

The research assistant also took observation notes during the session.

Older adults were screened based on their functional cognitive level. The Short Portable Mental Status Questionnaire (SPMSQ) (Pfeiffer, 1975) is a short questionnaire used to assess levels of intellectual functioning in older adults: a score of between 0 and 2 corresponds to intact intellectual functioning, 3 to 4 indicates mild intellectual impairment, 5 to 7 corresponds to moderate intellectual impairment and 8 to 10 indicates severe intellectual impairment. We wanted to investigate whether our tool could be used and whether it was appropriate for older adults with diverse abilities, so we only excluded participants with severe intellectual impairment so, for the purpose of the experiment, we chose participants with an SPMSQ score of below 7 . The caregivers verbally invited the inhabitants in the care home who fulfilled the criteria to participate in the study, explaining the details. The selected care home is a rather large structure so we were able to use only those who showed interest in participating on their own Table 2.

We recruited onsite younger adult visitors by word of mouth inside the care home. The younger adults participated in the study from the museum in Trento together with another research assistant at the museum who was responsible for helping them to use the tool. The young adults were offered free entrance to the museum in exchange for their help. They were relatives of the care home personnel or part of the personnel but not care givers or people working directly with the participants. They did not know the older adult participants personally, although they were quite familiar with the dynamics of the care home and the everyday life of the elderly there. We chose younger adults from the same area because of the cultural and linguistic affinity: building rapport would be much easier for younger people who come from the same area as the older adults. Additionally, people familiar with the everyday lifestyle in the care home, might know which topics could be potentially sensitive to older adults, something that an average museum visitor would not know.

\begin{tabular}{|c|c|c|c|c|}
\hline ID & Age & Gender & SPMSQ & Co-visitors \\
\hline $\mathrm{P} 1$ & 81 & Female & 2 & Visited with $\mathrm{P} 2$ and 1 onsite visitor \\
\hline $\mathrm{P} 2$ & 88 & Female & 1 & Visited with $\mathrm{P} 1$ and 1 onsite visitor \\
\hline P3 & 92 & Female & 0 & Visited with $\mathrm{P} 4$ and 1 onsite visitor \\
\hline $\mathrm{P} 4$ & 79 & Female & 2 & Visited with $\mathrm{P} 3$ and 1 onsite visitor \\
\hline P5 & 88 & Female & 0 & Visited with 1 onsite visitor \\
\hline $\mathrm{P} 6$ & 81 & Female & 5 & Visited with 2 onsite visitors \\
\hline P7 & 82 & Male & 5 & Visited with 2 onsite visitors \\
\hline P8 & 88 & Female & 0 & Visited with $\mathrm{P} 9$ and 1 onsite visitor \\
\hline P9 & 95 & Female & 3 & Visited with $\mathrm{P} 8$ and 1 onsite visitor \\
\hline $\mathrm{P} 10$ & 73 & Female & 1 & Visited with 1 onsite visitor \\
\hline P11 & 76 & Female & 0 & Visited with P12 and 1 onsite visitor \\
\hline $\mathrm{P} 12$ & 89 & Female & 1 & Visited with P11 and 1 onsite visitor \\
\hline $\mathrm{P} 13$ & 84 & Female & 0 & Did not participate due to audio problems \\
\hline P14 & 91 & Female & 2 & Did not participate due to audio problems \\
\hline $\mathrm{P} 15$ & 81 & Female & 1 & Decided not to participate just before the session \\
\hline
\end{tabular}

Table 2.

Demographics of study participants

P15 
Each session lasted around $45 \mathrm{~min}$, and we had 15 older adults that showed interest in participating. A total of 3 participants did not take part: 2 because of audio problems at the scheduled session and 1 did not feel like participating on the day, which left us with 12 participants in total. This is in line with existing research (Lazar et al., 2017) that recommends that distributed studies like ours, where the participants cannot come by themselves, should include approximately 10 participants.

\subsection{Measures}

We used the following measures for our study.

3.2.1 Engagement. The ICT-Sense of Presence Inventory (ICT-SOPI) questionnaire (Lessiter et al., 2001) is a technology-agnostic presence scale that consists of 46-items, each validated for independent use. We used the Engagement sub-scale (e.g. "I felt involved (in the displayed environment)", "I enjoyed myself", "My experience was intense").

3.2.2 Spatial presence. We also used the ICT-SOPI questionnaire here, using the Sense of Physical Space sub-scale measuring the sense of being located in another place, in this case the museum (e.g. "I had a sense of being in the scenes displayed", "I felt I could have reached out and touched things (in the displayed environment)").

3.2.3 Social closeness. The Inclusion of Other in Self scale (IOS) (Aron et al., 1992) is a single-item, graphical measure that shows two circles for self and others at various levels of distance until they substantially overlap. Our participants indicated which one best represents the perceived interaction with the onsite companions.

3.2.4 Enjoyment. Four items on a five-point Likert scale from the game experience questionnaire scale (De Kort et al., 2007) measured enjoyment in the experience (e.g. "I enjoyed the experience").

3.2.5 Onsite group data. We collected the following data regarding the onsite visitors:

- The position of each onsite member each second.

- The state of the system at each second, i.e. in drama, observe or just visiting 3. Audio recordings of the sessions.

We had three additional questions examining perceived suitability of the application for visiting museums remotely, usefulness for the envisioned task, and whether participants would use it for visiting other museums. Each item was a statement, and we invited participants to state the level up to which they agreed or disagreed with the statement on a five-point Likert scale, with 1 = "totally disagree" and 5 = "totally agree".

\subsection{Data collection}

All the scales of the independent measures were combined into one questionnaire that we administered to each participant when they finished the testing. We instructed the participants not to spend too much time thinking about the items, but just to fill them as fast as possible.

The onsite research assistant filled out a pre-defined observation form1, taking notes about what was happening during the experiment and what the remote participants were doing. The notes included whether participant (s) laughed in the session, whether they looked around, whether they talked to onsite participants, talked among themselves (in the sessions where two participants participated at the same time), whether they touched the screen and things presented on the screen, whether they talked on topic and whether they talked about things not related to the experience.

\section{Evaluating older adults' ability}


JSIT 22,4

336
We additionally had a semi-structured interview2, debriefing the participants on whether they liked the experience, which drama piece was their favourite and least favourite, what they would change, and if they had any additional comments about either the characters or the interface.

\subsection{Procedure}

Testing, approved by the University of Trento ethical committee, was conducted in diverse sessions at the care home of each participating older adult. After participants signed the informed consent form, the research assistant at the care home introduced the study and informed the participant(s) that they were helping researchers to test a software intervention for remote participation in museum visits by an onsite group from the same town. The research assistant informed the participant (s) that they would complete a questionnaire assessing the experience at the end of the study. She then introduced the application, explaining the way it would work. The participant (s) were told that the onsite visitors were watching the same museum content that they were watching. After being assured that the participants understood the purpose of the application, the research assistant established the link with the onsite visitors at the museum. The onsite visitors guided the participants through the visit, interacting directly with the participant (s)via audio channel communication, and indirectly by moving around the museum. A summary of the procedure used with the older adults is given in Table 3 . The research assistant at the museum used a similar procedure with the onsite participants to introduce them to the onsite visit

The research assistant at the care home observed the behaviour of the remote user (s) and took notes on potential design or communication problems.

The actual space where the activity took place in the care home significantly influenced the user experience, and how users perceived the system and interacted with it. While performing the study, we occupied different spaces inside the care home with different participants. In the first few days, one of the sessions took place in a common room for daily activities, and in the same room several other older adults were present at the time of testing. The participant was easily distracted by the events happening around her, and in general it was much more difficult to maintain focus on the activity. Some other sessions took place in more peaceful rooms, like the care home kitchen, or a quiet reading space. We believe that for an approach like ours to work in a care home, dedicated spaces should be assigned for these types of activities. Additionally, we believe that the caregivers and their attitude and approach played big role in adults' terms of acceptance of the system in the care home: personnel who are enthusiastic about the initiative create excitement about the experience in the participants as well.

The look of the onsite and the remote visitor application are presented in Plate 1 and Figure 1 respectively. The location of the onsite visitor inside the museum was tracked with the help of iBeacons carefully located next to objects. After the iBeacon is detected

\section{Table 3.}

The research assistant at the care home follows these procedural steps Procedure steps when introducing the 2 application to the 4 older adult $\quad 5$

The participant signs the consent form

General introduction by Research assistant 1 about the purpose of the study

Research assistantsat the care homeexplainto the older adult participant (s)how the tool works A link is established the onsite visitors The questionnaire is submitted to the participant at the end of the experiment 


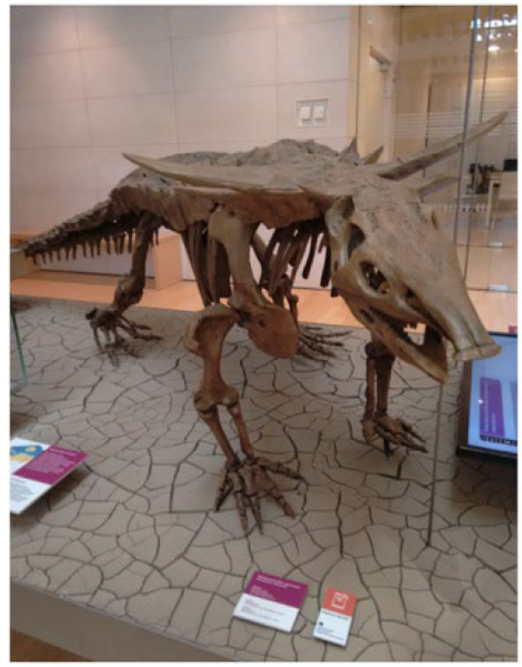

(a)

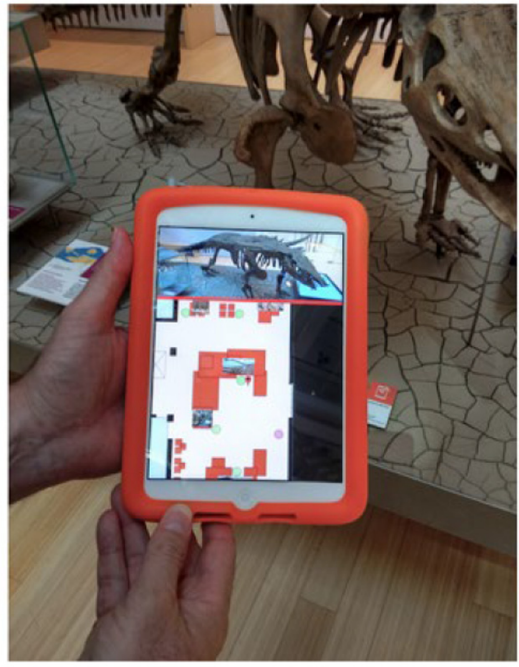

(b)
Evaluating older adults' ability

337

Plate 1.

An object inside the museum with an iBeacon next to it (a) and the onsite application after the iBeacon has been detected (b)

meaningful presentations are offered to the onsite visitors. The interface of the remote visitor app is in the form of a theatre stage and the "journey" to the museum starts with a small animation where the curtains on the stage open as in Figure 1(a). The theatre background picture is automatically updated based on the object in front of which the group is located, as depicted in Figure 1(b). If the participants are standing close to an object that has a story segment associated with it, the system enters into a drama state: the curtains close, the aliens appear on stage and an audio story segment starts as depicted in Figure 1(c).

\section{Results}

The three participants who did not finish the study and did not complete the questionnaire were omitted from data analysis, so our final data set contains 12 participants. Plate 2 depicts some of the participants while taking part in the study.

Data analysis was performed with the R statistical package. We calculated Cronbach's Alpha of the constructs to test if the items measure the same construct, and to measure the internal consistency (Santos, 1999). The reliability of the 4 scales that were used in the questionnaires is acceptable (Table 4, Cronbach's Alpha $>0.4$ ), therefore, the items belonging to each scale seem to describe one construct and all scales can be calculated as mean scores. Taking into account that Social Closeness was measured only by one item, we could not calculate Cronbach's alpha for it. We report on the means and standard deviation of each construct in Figure 2.

Through ANOVA, we tested whether age had any significant effect on our dependent variables, but no correlation was found.

Next, we looked at the correlations between independent variables. We found that Enjoyment correlates significantly with Engagement $(r(12)=0.834, p<0.001)$ and Social Closeness $(r(12)=0.605, p<0.05)$. Social Closeness also correlated with Engagement $(r(12)=$ $0.605, p<0.05)$ and Enjoyment $(r(12)=0.594, p<0.05)$ but not with Spatial presence. Furthermore, Engagement correlates significantly with Spatial Presence $(r(12)=0.660, p<0.05)$ 


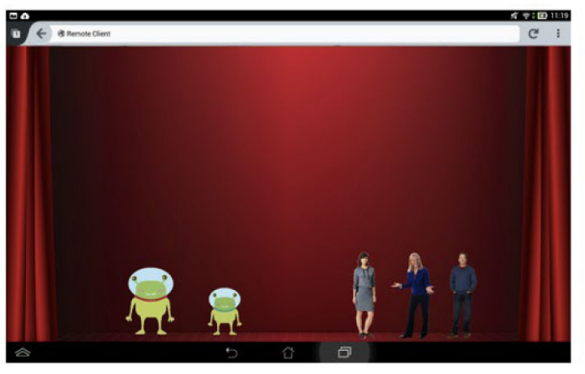

(a)

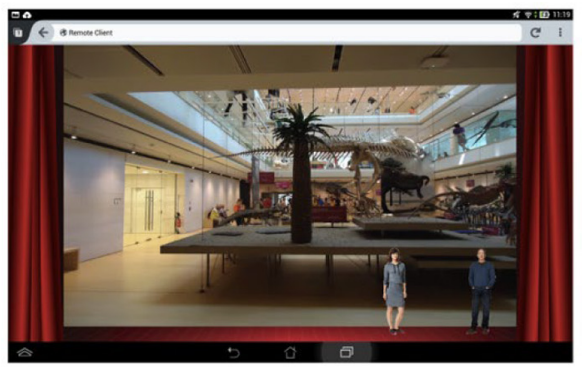

(b)

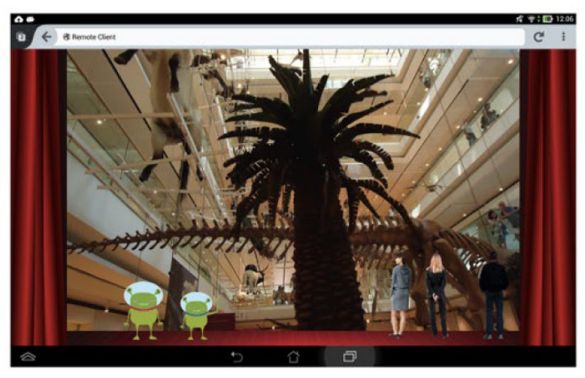

(c)

Notes: (a) Interface of the remote visitor app is in the form of a theatre stage in which the onsite visitors are depicted on the stage; (b) the background is automatically updated with a

Figure 1.

Remote visiting application picture of the object that the onsite visitors sees (c), when there is a story segment associated with this object, the system enters in drama state, the group starts to listen to a story segment, the onsite participants are facing the object and there are aliens on the stage, telling the story of the object

and Enjoyment correlates significantly with Spatial Presence $(r(12)=0.622, p<0.05)$. What we understood from this is that within the use of our tool, the constructs of Engagement, Enjoyment and Social Closeness are highly correlated, whereas the constructs of Social Closeness and Spatial Presence do not seem to correlate. How close participants felt with the onsite visitors did not affect their feeling of "being there" with our drama-based approach and vice versa.

Additionally, drama was positively received by the older adults. We gathered general data on the three extra questions, examining usefulness, suitability of the application and whether they would use the application again for visiting other museums, we got high scores, which only confirmed the suggestion that participants really liked the experience and found the application useful and suitable for the task. The results are summed in Figure 3.

Next, we analysed the data we gathered from the observation notes. We treat the data by summing it across the different categories of behaviour we observed. The observation notes told us that all the participants talked with the onsite visitors, except for one who felt that the approach was not for her, and relied on her friend in the session. Participants mainly talked on topic, often introducing other topics too, but always having the topic of the exhibit as a starting point and inspiration. Two participants barely talked about the museum content, but instead always used the presented topics to start talking about their own life experiences. Mainly participants laughed, with few participants being serious all the time, although they positively 


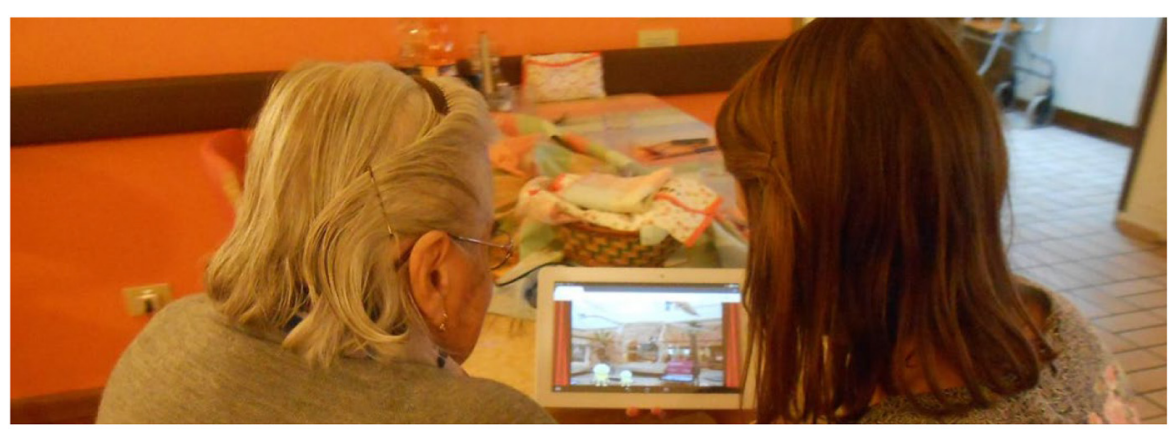

(a)

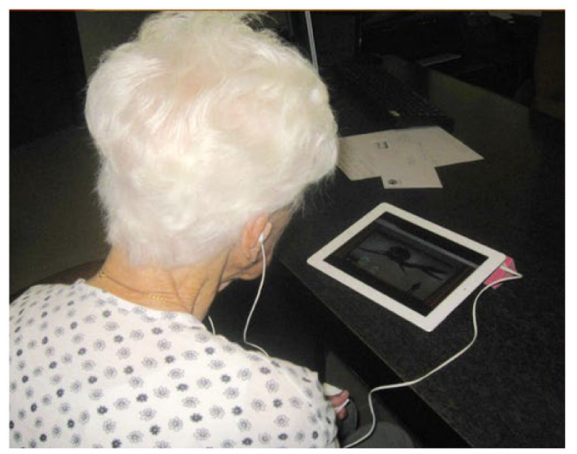

(b)

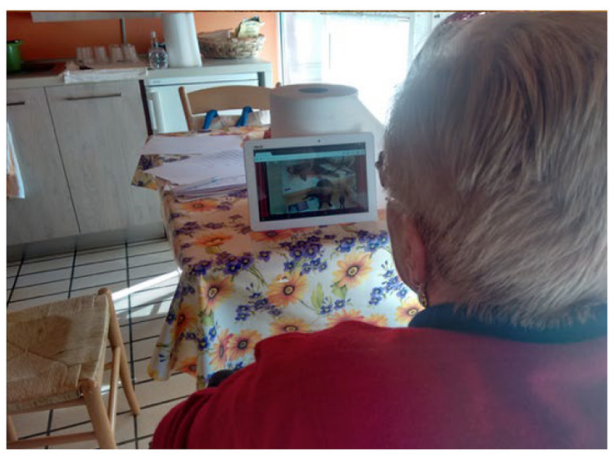

(c)
Evaluating older adults' ability

Plate 2.

Research assistant at the care home explains participant how the application works
Scale/Construct

Enjoyment

Engagement

Presence

Social Closeness
Cronbach's alpha
Table 4. Cronbach's alpha of each construct

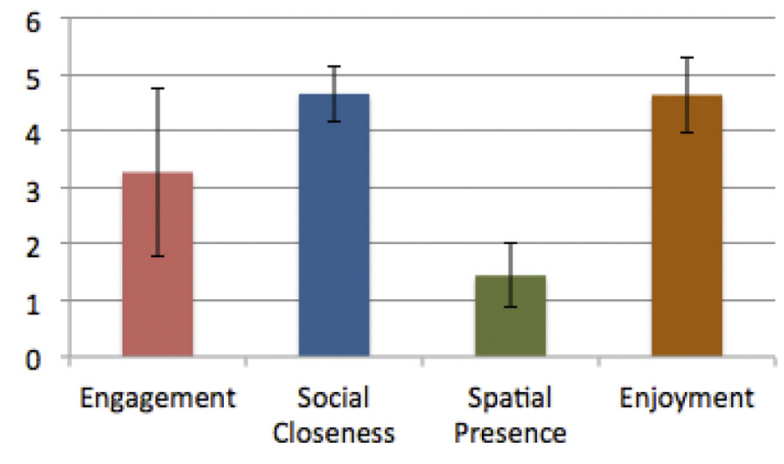

Figure 2.

Means and standard deviations of the constructs measured in the study 
JSIT

22,4

340

Figure 3.

Summary of the additional questions in the questionnaire, examining usefulness, stability and preference for using the application again

\section{Figure 4.}

Two sets of circles (blue and red) represent the paths of two onsite visitors visiting together as a group evaluated the experience. Only three looked around the room (while the others looked only at the screen) during the experiment which came as further confirmation that our approach was interesting for the participants.

In Figure 4 we show the log of one of the groups that had two onsite visitors while visiting the museum together with participant P7. We had only two groups of two people inside the museum, so we couldn't test whether different patterns on moving inside the museum influenced the older adult's experience. In these cases, (as in Figure 4) the group members stayed close to each other and didn't feel like separating, although they were instructed that they could if they wanted. Mammalian exhibits were present in the bottom right of the map, and these were the places where onsite visitors usually spent the most time in the museum while touring with remote visitors. We observed that remote participants had fun in this scenario however future research is needed to demonstrate this.

We subjected the audio logs to thematic content analysis (Anderson, 2007) to illuminate what constitutes an interesting visit for older adults. In our analysis, the focus was on the content of the talks, excluding the drama pieces, and on what was said in the conversations.
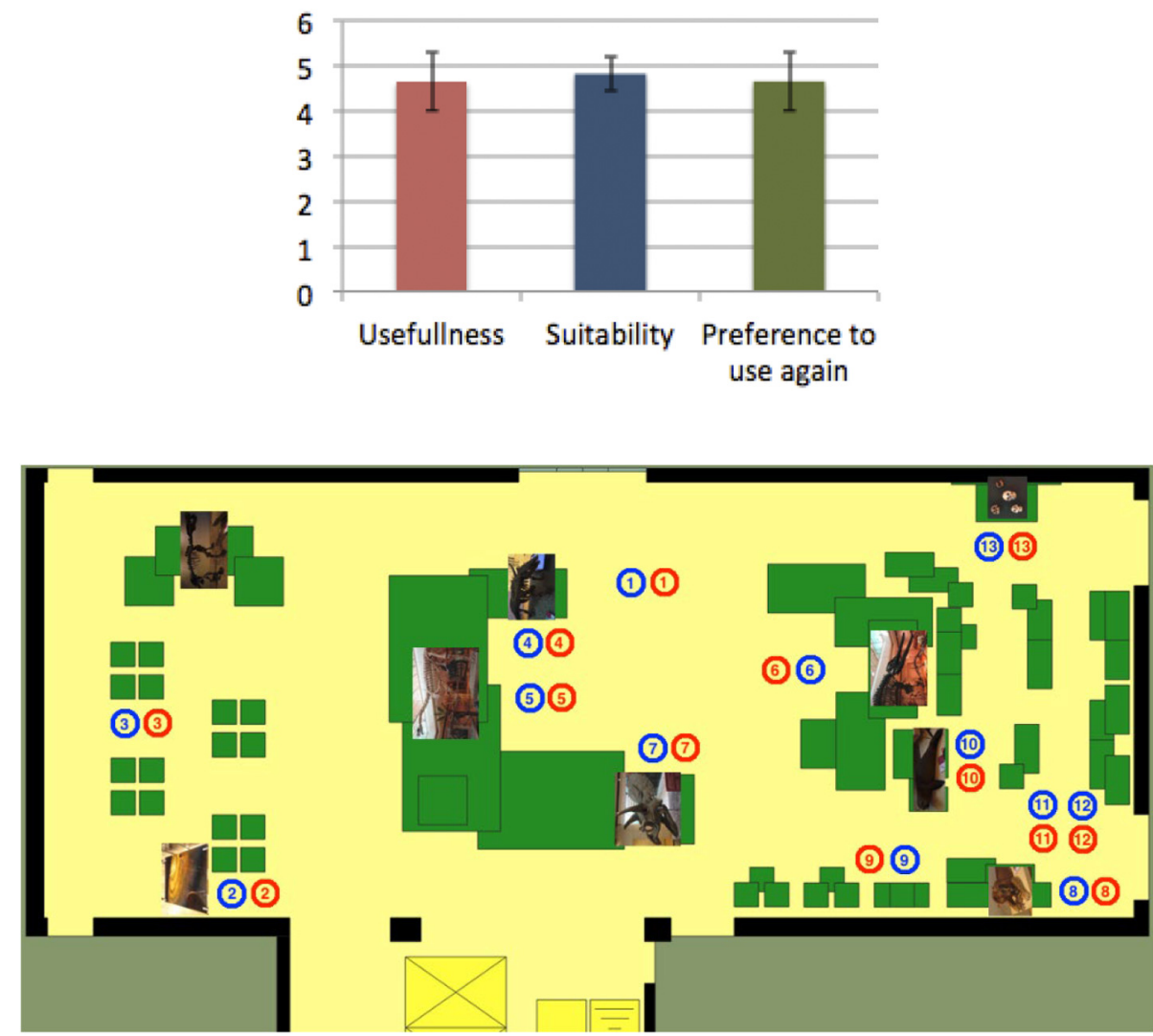

Notes: Each circle depicts a position where onsite visitors stopped for more than 5 seconds. The circles are in chronological order. Drama segments were played in position 1, 2, 5, 8 and 13 
Themes were generated and grouped into categories, and we detected several topics emerging as most interesting to older adults. Animals, and mammals in particular, were the most popular theme, with participants asking for additional details about their fur, skin, and differences in reproduction. Next, were dinosaurs, where the discussions were mainly about how old they were, their teeth, and their actual size. Participants additionally showed curiosity and asked about life on other planets, the chemical composition of the Earth and astronomy. The results are summarized in Table 5.

Next, we analysed who initiated conversations in the sessions and how many of the conversations were initiated by the onsite visitors and how many by the remote visitors. The results are summarized in Table 6 . Talk was predominantly initiated by the onsite visitors in only 2 of the groups: P1 and P2 (5 out of 6 times), and P5 (6 out of 10). In 5 of the groups the conversations were predominantly initiated by the remote visitors: P3 and P4 (11 out of 13), P5 (6 out of 8), P7 (10 out of 13), P8 and P9 (8 out of 12), P10 (5 out of 9 ) and P11 and P12 (6 out of 11). Conversation was equally initiated by both sides in the session of P6 (talking was initiated 7 times by both sides). This told us that participants were curious about the presented themes.

Post interviews with the participants told us that they all liked the experience, except for one that found it not suitable for her because of her age and health problems. The most favourite story segments were: the story about the lioness ( 7 people), dinosaurs ( 3 people), and formation of the planet Earth (1 person). They all liked the approach, but with one participant indicating that she prefers plain facts, and 4 participants specifying that they liked visiting with a story, just not necessarily with aliens. Some commented about the elements on the interface, that they liked the opening and closing of the curtains, and said
Evaluating older adults' ability

\begin{tabular}{lllr}
\hline Theme & N. of mentions & Who mentioned & \\
\hline Animals and mammals & 8 mentions & P1, P2, P3, P4, P6, P7, P11, P12 & \\
Dinosaurs & 7 mentions & P1, P2, P5, P6, P7, P8, P10 & Table 5. \\
Life on other planets & 6 mentions & P3, P4, P8, P9, P11, P12 & Thematic content \\
Chemical composition of Earth & 6 mentions & P1, P2, P5, P9, P8, P10 & analysis results \\
Astronomy & 5 mentions & P3, P4, P5, P7, P9 & \\
\hline
\end{tabular}

\begin{tabular}{|c|c|c|c|c|c|c|c|c|}
\hline ID & Laugh & $\begin{array}{l}\text { Look } \\
\text { around }\end{array}$ & $\begin{array}{l}\text { Talk to } \\
\text { visitors }\end{array}$ & Talk to peer & Touch screen & Talk on topic & $\begin{array}{c}\text { Talk on different } \\
\text { topic }\end{array}$ & \\
\hline P1 & $\checkmark$ & $\checkmark$ & $\checkmark$ & $\mathrm{x}$ & $\mathrm{x}$ & $\checkmark$ & $\checkmark$ & \\
\hline P2 & $\checkmark$ & $\checkmark$ & $\checkmark$ & $\mathrm{x}$ & $\mathrm{x}$ & $\checkmark$ & $\checkmark$ & \\
\hline P3 & $\checkmark$ & $\mathrm{X}$ & $\checkmark$ & $\checkmark$ & $\mathrm{x}$ & $d$ & $\mathrm{x}$ & \\
\hline $\mathrm{P} 4$ & 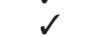 & $\mathrm{X}$ & 2 & 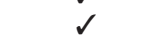 & $\checkmark$ & 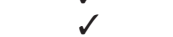 & $\checkmark$ & \\
\hline P5 & $\checkmark$ & X & $\checkmark$ & NA & $\mathrm{x}$ & $\checkmark$ & $\checkmark$ & \\
\hline $\mathrm{P} 6$ & 2 & $\mathrm{X}$ & 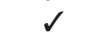 & NA & $\mathrm{x}$ & 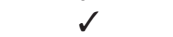 & $\mathrm{x}$ & \\
\hline P7 & 2 & $\mathrm{x}$ & 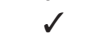 & NA & $\mathrm{x}$ & 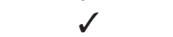 & $\checkmark$ & \\
\hline P8 & $\mathrm{x}$ & $\mathrm{x}$ & $\checkmark$ & $\checkmark$ & $\mathrm{x}$ & $\checkmark$ & $\mathrm{x}$ & \\
\hline P9 & $\mathrm{x}$ & $\checkmark$ & $\mathrm{x}$ & $\checkmark$ & $\mathrm{x}$ & $\mathrm{x}$ & $\checkmark$ & \\
\hline P10 & $\checkmark$ & $\mathrm{x}$ & $\checkmark$ & NA & $\checkmark$ & $\checkmark$ & $\mathrm{x}$ & \\
\hline P11 & $\mathrm{x}$ & $\mathrm{x}$ & $s$ & $\checkmark$ & $\mathrm{x}$ & 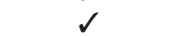 & $\mathrm{x}$ & Table 6. \\
\hline P12 & $\mathrm{x}$ & $\mathrm{x}$ & $\checkmark$ & $\checkmark$ & $\mathrm{x}$ & $\mathrm{x}$ & $\checkmark$ & Observation notes \\
\hline Total & 8 & 3 & 11 & 6 & 2 & 10 & 7 & summary \\
\hline
\end{tabular}


JSIT

22,4

342

that they would prefer to see it on a bigger screen so they could better see the details and the people on the stage.

Visitors at the museum itself were very interested in the potential of the system to help the elderly socialize, and were happy to assist elderly shut-ins enjoy a virtual experience that would be impossible physically. Local participants also deferred to the remote user when it was obvious that the remote user was more active, for instance answering questions like a tour guide, but easily reverted to taking charge when they sensed pauses in the conversation. However, local participants were also easily frustrated when network congestion caused problems with dropped audio or bad echo cancellation, and they had problems distinguishing when there was network congestion versus other problems on the remote side (e.g. inattention, quiet talking, or remote disturbances). In fact, a high-quality audio connection was essential for the proper functioning of the overall interaction. Other causes of frustration included loud noise in the museum, such as when groups of children were nearby, presentations that interrupted ongoing conversation, and being uncertain that the remote elderly could actually see the same thing they saw on their local tablet. Plate 3 depicts two of the onsite participants while taking part in the experiment.

Results are discussed further (together with the observation data) according to our five research questions outlined previously.

\subsection{RQ1: Is a drama-based visit an enjoyable experience for the older adult?}

In general, we found a high degree of enjoyment among the participants. Participants liked the visit and they had fun. They laughed at some of the jokes in the story, and enjoyed the quest of the aliens. Some of them found the story and the scientific facts nicely integrated. Our non-traditional alien "guides" on the museum visit attracted attention to our participants, and each session started with the elderly people curiously questioning what

\section{Plate 3.}

Onsite visitors participating in the experiment

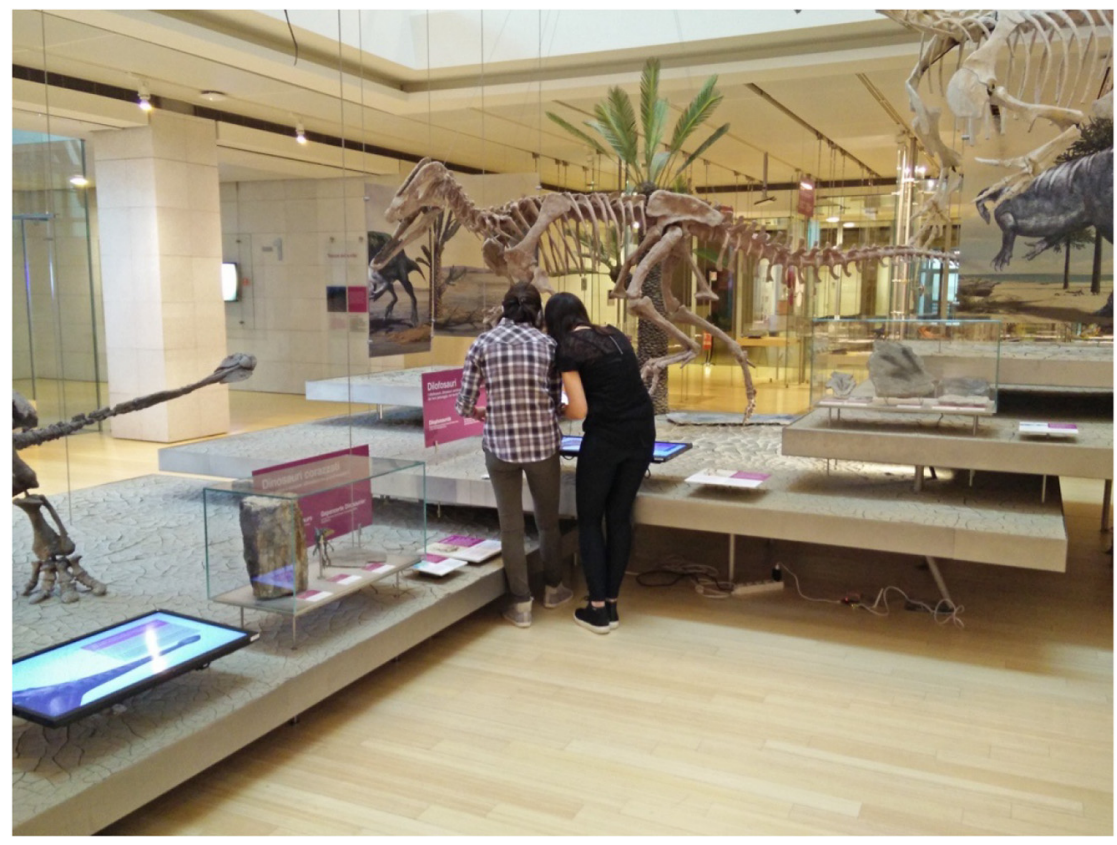


and who they were. Although some of our participants didn't know whether aliens existed, they still found the whole experience entertaining and expressed a desire to repeat it again. The interactions between visitors (remote and onsite) indicated a high level of overall enjoyment, allowing users to focus on both looking at the exhibits and talking to each other. Some older adults tried to make additional new jokes, besides the ones told by the aliens, which made the whole experience even more fun. One example: "If you saw real dinosaurs like this, you wouldn't be able to sleep in your bed at night!"

Sometimes some of the story segments were too long, and both onsite and older adult participants found this boring. Some of the participants suggested having videos instead of static photos, or a slideshow of several photos changing over time to follow the story flow. Additionally, some participants told us that although they found this experience interesting, they would like to see other types of museums, and expressed interest in museum exhibitions about art or crafts. Some of the participants told us that they would also like to see more simple information in the form of written text, and showed a preference for pure facts over an interactive approach.

\subsection{RQ2: Do older adults feel engaged during a drama-based remote visit?}

Participants expressed their points of view about the exhibits presented, commenting primarily on the content of the museum. The drama pieces, together with the pictures of the objects and the people onsite, allowed the elderly to deepen their interest in, and develop curiosity for, the exhibits that they saw. We also observed that the participants not only discussed the facts presented, but reasoned about them too. For instance, some participants asked what kind of consequences these scientific findings have on how we live nowadays, and how they could improve life and well-being. Many participants told us that they found the themes of the exhibition good for their memory, that they included things that they had studied in the past, and the experience of the tour brought back those memories.

We ascertained that our drama-based approach also has some limitations. The connectors that followed story segments sometimes stopped discussion rather than promote it. These were timed to start a certain number of seconds after the story segment, so when a connector started and the people happened to be in discussion, it would stop them in the middle of their conversation. This was a drawback especially for those elderly that forgot what they wanted to say after the connector. Another limitation of the approach is that when the onsite people spoke, the elderly didn't want to interrupt them even though they had something they wanted to ask. Sometimes also the older adults were making facial experiences, for instance approving and disapproving with what was said in the story or by the onsite participants, and the onsite participants were not aware of it and even perceived it as a lack of participation. It is possible that having a small video stream of the elderly may allow the onsite visitors to determine their intent.

\subsection{RQ3: Do older adults experience spatial presence in a drama-based remote visit?}

Our intuition was not confirmed, and our study revealed that our system didn't score highly on the construct of spatial presence. Our participants didn't feel as though "they are there" in the displayed environment. We believe that not having a continuous flow of images (a limitation of the proximity-based positioning system we used) was the main cause for the lack of appreciation of the spatial rendering factor. In the lengthy intervals between presentations while people walked in areas where there were no detectable objects, there was no novel visual information provided remotely, and this we believe negatively contributed to the sense of being there.

Some of the participants showed additional curiosity and asked for more information about the real size of the skeletons and preserved animals found in the museum, and asked additional questions about the animals that were partially shown in the images, or about the actual
Evaluating older adults' ability 
JSIT 22,4

arrangement of the objects in the museum. Some of the remote participants admired the onscreen images and tried to reach out and "touch" the objects they saw, or for instance tried to "caress" the lioness exhibit.

\subsection{RQ4: Do remote participants experience social closeness with the rest of the group in a drama-based visit?}

The results show that the older adults felt as though they were with someone and the feeling of experiencing social closeness was quite high. In our experiment, people participated not only as individuals, but as part of a social group, going for a visit of a museum together. Being together with other people in the shared activity of visiting a museum created a more subjective feeling of group, and created a feeling of togetherness that was reflected by both onsite and remote visitors in their questionnaire.

\subsection{RQ5: Do the dynamics of the onsite group influence the experience of the remote participant(s)?}

The groups typically stayed together throughout the visit and there was usually a strong overall tendency for maintaining the coherence of the group. Owing to the difficulty in recruiting participants, we could not test for significant differences between conditions where the onsite groups are of various sizes (we had only two groups with 2 onsite visitors, and the rest with 1). What we observed is that there was much more interaction and communication when the onsite group consisted of two people, and in general the experience was more fun as observed by the research assistants involved in the testing. We observed the same dynamic when two elderly adults participated together from the care home.

\section{Discussion}

This study investigated the use of a system by older adults with mobility constraints to remotely participate in a museum visit from a care home. Most importantly the study showed that the technology successfully and fundamentally integrates the older adult into the fabric of the visit. The experienced levels of engagement, enjoyment and social closeness confirm that we are on the right track, and thus that our technology holds promise for improving the lives of the elderly. When we explored the relationship between the different aspects of the user experience, we found an effect of social presence and enjoyment on engagement. We take a look at what this means for the relationships between constructs to try to provide an explanation.

\subsection{Practical implications}

The collaboration that occurred between onsite and remote visitors, and including a range of objects from the environment along with the interactive story, played a central role in how participants experienced the museum. Through social interactions the museum visit evolved, not only as a place where knowledge is presented, but where a short authentic experience occurred. Our participants reported that visiting while listening to drama was fun, and a large part of the interaction revolved around elaborate descriptions of personal interpretations of the observed content, not just the facts covered by the story. We believe that both the audio channel and the interactive story were important for creating an affective virtual experience: the audio channel increased the sense of togetherness, while the interactive story made the visit more fun. The theatre interface aided the creation of this affective experience, with some participants commenting that they found it stimulating and an interesting way to convey the narrative of the museum. 
Our overall findings from the experiment indicated that the participants really liked the experience and were really happy to be given the opportunity. Continuous interaction and communication were necessary during the visit and we believe that this is the main reason that the interactive visit was interesting. During the visit, the participants sometimes interacted a lot (e.g. while seeing content of particular interest to them) and sometimes interacted a little less (e.g. while seeing content of less interest). In general, our older adult participants took a proactive stance and used the occasion to ask a lot of questions. Some of them commented: "They [the people from the care home] won't take us for an excursion to the museum, Trento is far away, this is the only way to see all these things before we die". Some of them found the process enjoyable and a good opportunity to reminiscence about topics they have explored by reading in the past.

Our participants felt as though there was a mediation channel with onsite visitors in the museum but did not feel as if they were inside the museum. According to some presence theories (Benyon et al., 2014), presence is a function of our experience of a given medium (Media Presence), and specifically the "illusion of non-mediation" is produced by the disappearance of the medium from the conscious attention of the participant. For our experiment we used tablets, whose small screen was a barrier to presence, and as a mediating tool it influenced the level of presence felt in this mediated experience. We believe that a bigger screen or more immersive technology could provide a better experience. Additionally, a bigger screen would allow participants a better view of the objects So that they could explore additional details in further depth.

We also understood that we could improve the museum experience greatly by providing diverse techniques for narrative presentation. Providing drama was fun, but providing only static images was not enough. More dynamic visualisations and interactive multimedia (that fully occupy the attention of the users) should be considered to make the story more engaging for our remote participants. Additionally, we understood that the system needs to adapt to the participants themselves. This requires that the system is made aware of the behaviour of its users and is able to subsequently adapt to those behaviours. For instance, our drama connectors were scheduled to start exactly one minute after the conclusion of the drama, and sometimes instead of helping conversation they supressed it. We understood that such events should be scheduled based not only on time, but also based on observed behaviour, such as ongoing conversation.

Participants in general noted and reacted to the change in the presentation of the images of onsite participants on the screen. The orientation where the group is facing the remote participants was a greater invitation to start a conversation, and it made the participants feel more comfortable in initiating a discussion. Participants rarely started a conversation when the onsite group was depicted as facing the object, it mainly happened in groups in which there was no interest in the drama.

We observed that the number of participants on each side of the system influenced the levels of experienced engagement and enjoyment for both onsite and remote visitors, although we didn't gather enough data to statistically support this intuition. In general, we observed that the sessions in which two older adults were sitting together were more fun and more engaging than the sessions in which we had only one older adult participant. We observed the same pattern when two people were visiting the museum together compared with one onsite visitor. In both scenarios we observed much richer social dynamics compared to the scenarios when there was only one person on each side. Being together with friends in a real shared activity, such as a party, creates a more subjective feeling of being together in the experience that goes beyond experiencing the party alone. We tried to design
Evaluating older adults' ability 
JSIT 22,4

technology in this paper that is about supporting groups while they visit a museum, but a more controlled experiment is needed in order to understand if multiple remote participants will create a better experience.

Participants found the drama approach appealing and engaged in further discussion around the presented material. They also expressed a preference for seeing other types of museum or other distant places. As one of the participants commented: "I have found the system very useful and would use it again for seeing other museums too". One participant, fond of painting, expressed a wish to visit a modern art museum, or to visit the Venice Biennial. Another participant inspired by our approach suggested that we also offer interactive visits to zoos. From this we also understood that our system could be seen as an extension to a real place, a magical door to places where older adults would like to go. We plan to explore this possibility, visiting not only museums but any distant places, in future research.

We believe that theme of the museum seemed interesting to our participants and it solicited interest. We do not have statistical evidence, but from several studies we have conducted in the past it seemed that themes connected with history, evolution like in our case, old crafts evoke interest in all older adult participants, while art museum evokes interest only in participants that already have interests in art in general. In this study indeed some older adults that are fond of art asked for the possibility to visit an art museum. We have the intuition that some themes are universally accepted and some based on personal interest. This would be of interest to be tested in future works.

\subsection{Limitations}

The research presented in this paper has a number of limitations. The study involved 12 older adults, a relatively small sample. A bigger sample is needed to understand whether the findings are generalisable to larger audiences and to make a significant theoretical contribution. Our older adults were generally proactive, and well educated, so they may not be representative of the older adult population. Future work is needed to see whether our findings hold for larger, more diverse samples of older adults. In addition, we learned that technology for scenarios like ours has to work perfectly. Our implementation was not perfect, specifically we had no VoIP expertise, and there were frequent changes in the audio levels (mainly because of internet congestion) that affected the experience. The participants complained when the quality of the audio was not good enough. We had to postpone two sessions because of poor connectivity and thus bad audio quality. We plan to address these technical problems with future development efforts to assure the stability of the system.

An additional limitation of our approach is that we did not provide a way in which our participants would feel as if they were in control of the visit. They had the option of communicating verbally any desire to see something specific, but they could not move on their own inside the "virtual museum". They felt as if they were actively participating on the visit, but they could not change the flow of events. This was confirmed by our observations, where one of the participants commented: "[Onsite visitor name], you are in charge, you are in control!" Or another: "It was fun, but we could not do anything." We decided not to implement this feature from our experience that allowing control by older adults would most likely only confuse them (Kostoska et al., 2015). We believe that the remote interface should adapt to the capabilities of the remote user. The next step in our work would be to study ways to allow both sides to take control of the visit and mutually shape the experience.

\subsection{Future directions}

We would like to discuss how our drama approach could influence the general research goal of social inclusion of older adults with mobile constraints, not only as a service for visiting a 
museum as we present here, but as a wider goal to ensure well- being and independence of older people at home (a goal not addressed in our study). To this end, future research with longterm use is needed to determine whether people enjoy and engage in experiences like the one we proposed here over the long term and whether it affects the well-being of the elderly. This future work will have to include in-depth qualitative and quantitative measures to estimate the effect of systems like ours on the factors associated with quality of life for older adults and realistically perceived social support. In the future where we will face the challenge of an aging population, ICT-based solutions for older people in their homes will become more and more common. In our experiment, we observed that engagement and participation occurred by both the onsite visitor(s) and remote visitor(s), which shows that an approach like ours has the potential to be helpful for social inclusion of the elderly, helping them to overcome spatial and social barriers.

\section{Conclusions}

In this experiment we explored whether older adults are able to remotely participate in museum visits from home, and explored further concepts such as engagement, enjoyment, and presence in a remote museum visit using virtual environments. We showed that the participants had positive experience using our system. Not only did this study indicate that we are on the right track in designing technologies for cultural heritage visitation for older adults, but it also provided confirmation that we provided value to our participants, as they expressed the will to use the system again. We found evidence that remote participants feel as if they are part of a group visiting the museum, and that they engage in them and enjoy the virtual visits. Our museum visits proved to be highly interactive experiences in which the remote participant engages, but we understand from our results that this engagement can be attained only if they enjoy themselves and feel part of the group, and vice versa.

Given the initial positive feedback, the overall preference by participants for seeing more museums in this fashion, and the lack of insurmountable drawbacks, our interface appears to be a suitable approach for designing technology for visiting museums for older adults and lowering their levels of social isolation.

\section{References}

Aljaroodi, H.M., Adam, M.T., Chiong, R. and Teubner, T. (2019), "Avatars and embodied agents in experimental information systems research: a systematic review and conceptual framework", Australasian Journal of Information Systems, Vol. 23.

Anderson, R. (2007), “Thematic content analysis (TCA)", Descriptive Presentation of Qualitative Data, pp. 1-4.

Antón, C., Camarero, C. and Garrido, M.J. (2018), "Exploring the experience value of museum visitors as a co-creation process", Current Issues in Tourism, Vol. 21 No. 12, pp. 1406-1425.

Aron, A., Aron, E.N. and Smollan, D. (1992), "Inclusion of other in the self-scale and the structure of interpersonal closeness", Journal of Personality and Social Psychology, Vol. 63 No. 4, p. 596.

Barbosa Neves, B., Franz, R., Judges, R., Beermann, C. and Baecker, R. (2019), "Can digital technology enhance social connectedness among older adults? A feasibility study", Journal of Applied Gerontology, Vol. 38 No. 1, pp. 49-72.

Beer, J.M. and Takayama, L. (2011), "Mobile remote presence systems for older adults: acceptance, benefits, and concerns", Proceedings of the 6th international conference on Human-robot interaction, pp. 19-26.

Benyon, D., Quigley, A., O’Keefe, B. and Riva, G. (2014), "Presence and digital tourism”, AI and Society, Vol. 29 No. 4, pp. 521-529. 
JSIT 22,4

Biocca, F., Harms, C. and Burgoon, J.K. (2003), "Toward a more robust theory and measure of social presence: review and suggested criteria", Presence: Teleoperators and Virtual Environments, Vol. 12 No. 5, pp. 456-480.

Callaway, C., Stock, O. and Dekoven, E. (2014), "Experiments with mobile drama in an instrumented museum for inducing conversation in small groups", ACM Transactions on Interactive Intelligent Systems ( Systems), Vol. 4 No. 1, pp. 1-39.

Cotten, S.R., McCullough, B. and Adams, R. (2011), "Technological influences on social ties across the lifespan”, Handbook of Lifespan Psychology, Springer Publishers, pp. 647-671.

Cotton, S.R., Anderson, W.A. and McCullough, B.M. (2012), "The impact of ICT use on loneliness and contact with others among older adults", ISARC. Proceedings of the International Symposium on Automation and Robotics in Construction, Vol. 29, IAARC Publications, p. 1.

D'Alba, A. and Jones, G. (2013), "Analyzing the effects of a 3d online virtual museum in visitors' discourse, attitudes, preferences, and knowledge acquisition", Cases on 3D Technology Application and Integration in Education, IGI Global, pp. 26-47.

De Kort, Y.A., IJsselsteijn, W.A. and Poels, K. (2007), "Digital games as social presence technology: development of the social presence in gaming questionnaire (SPGQ)", Proceedings of PRESENCE, 195203, pp. 1-9.

Decock, J., Van Looy, J., Bleumers, L. and Bekaert, P. (2014), “The pleasure of being (there?): an explorative study into the effects of presence and identification on the enjoyment of an interactive theatrical performance using omnidirectional video", Ai and Society, Vol. 29 No. 4, pp. 449-459.

Díaz-Rodríguez, N. and Pisoni, G. (2020), "Accessible cultural heritage through explainable artificial intelligence", 11th Workshop on Personalized Access to Cultural Heritage.

Dragojevic, M., Gasiorek, J. and Giles, H. (2015), "Communication accommodation theory", The International Encyclopedia of Interpersonal Communication, pp. 1-21.

Ens, B., Lanir, J., Tang, A., Bateman, S., Lee, G., Piumsomboon, T. and Billinghurst, M. (2019), "Revisiting collaboration through mixed reality: the evolution of groupware", International Journal of Human-Computer Studies, Vol. 131, pp. 81-98.

Falk, J.H. (2016), Identity and the Museum Visitor Experience, Routledge.

Garattini, C., Wherton, J. and Prendergast, D. (2012), "Linking the lonely: an exploration of a communication technology designed to support social interaction among older adults", Universal Access in the Information Society, Vol. 11 No. 2, pp. 211-222.

Gorini, A., Capideville, C.S., De Leo, G., Mantovani, F. and Riva, G. (2011), "The role of immersion and narrative in mediated presence: the virtual hospital experience", Cyberpsychology, Behavior, and Social Networking, Vol. 14 No. 3, pp. 99-105.

Holtfreter, K., Reisig, M.D. and Turanovic, J.J. (2017), "Depression and infrequent participation in social activities among older adults: the moderating role of high-quality familial ties", Aging and Mental Health, Vol. 21 No. 4, pp. 379-388.

Hope, A., Schwaba, T. and Piper, A.M. (2014), "Understanding digital and material social communications for older adults", Proceedings of the SIGCHI Conference on Human Factors in Computing Systems, pp. 3903-3912.

Katifori, A., Karvounis, M., Kourtis, V., Perry, S., Roussou, M. and Ioanidis, Y. (2018), “Applying interactive storytelling in cultural heritage: opportunities, challenges and lessons learned", International Conference on Interactive Digital Storytelling, Springer, Cham, pp. 603-612.

Kostoska, G., Baez, M., Daniel, F. and Casati, F. (2015), "Virtual, remote participation in museum visits by older adults: a feasibility study", 8th International Workshop on Personalized Access to Cultural Heritage (PATCH 2015), ACMIUI 2015, pp. 1-4.

Kostoska, G., Vermeeren, A.P., Kort, J. and Gullström, C. (2016), "Video-mediated participation in virtual museum tours for older adults", 10th International Conference on Design and Emotion, 27-30 September 2016, The Design and Emotion Society, Amsterdam. 
Kostoska, G., Fezzi, D., Valeri, B., Baez, M., Casati, F., Caliari, S. and Tarter, S. (2013), "Collecting memories of the museum experience", CHI'13 Extended Abstracts on Human Factors in Computing Systems, pp. 247-252.

Lazar, J., Feng, J.H. and Hochheiser, H. (2017), Research Methods in Human-Computer Interaction, Morgan Kaufmann.

Lessiter, J., Freeman, J., Keogh, E. and Davidoff, J. (2001), “A cross-media presence questionnaire: the ITC-Sense of presence inventory", Presence: Teleoperators and Virtual Environments, Vol. 10 No. 3, pp. 282-297.

Perry, S., Roussou, M., Economou, M., Young, H. and Pujol, L. (2017), "Moving beyond the virtual museum: engaging visitors emotionally", 2017 23rd International Conference on Virtual System and Multimedia (VSMM), IEEE, pp. 1-8.

Peters, E., Heijligers, B., de Kievith, J., Razafindrakoto, X., van Oosterhout, R., Santos, C., Mayer, I. and Louwerse, M. (2016), "Design for collaboration in mixed reality: technical challenges and solutions", 2016 8th International Conference on Games and Virtual Worlds for Serious Applications (VS-GAMES), IEEE, pp. 1-7.

Pfeiffer, E. (1975), "A short portable mental status questionnaire for the assessment of organic brain deficit in elderly patients", Journal of the American Geriatrics Society, Vol. 23 No. 10, pp. 433-441.

Pisoni, G., Daniel, F., Casati, F., Callaway, C. and Stock, O. (2019), "Interactive remote museum visits for older adults: an evaluation of feelings of presence, social closeness, engagement, and enjoyment in an social visit”, 2019 IEEE International Symposium on Multimedia (ISM), IEEE, pp. 99-993.

Roussou, M. and Katifori, A. (2018), "Flow, staging, wayfinding, personalization: evaluating user experience with mobile museum narratives", Multimodal Technologies and Interaction, Vol. 2 No. 2, p. 32.

Rubino, I., Barberis, C., Xhembulla, J. and Malnati, G. (2015), "Integrating a location-based mobile game in the museum visit: evaluating visitors' behaviour and learning", Journal on Computing and Cultural Heritage (Heritage), Vol. 8 No. 3, pp. 1-18.

Santos, J.R.A. (1999), “Cronbach's alpha: a tool for assessing the reliability of scales", Journal of Extension, Vol. 37 No. 2, pp. 1-5.

Schall, A., Tesky, V.A., Adams, A.K. and Pantel, J. (2018), "Art museum-based intervention to promote emotional well-being and improve quality of life in people with dementia: the ARTEMIS project", Dementia, Vol. 17 No. 6, pp. 728-743.

Skydsgaard, M.A., Møller Andersen, H. and King, H. (2016), "Designing museum exhibits that facilitate visitor reflection and discussion", Museum Management and Curatorship, Vol. 31 No. 1, pp. 48-68.

Van Dijk, B., Zwiers, J., Op den Akker, R., Kulyk, O., Hondorp, H., Hofs, D. and Nijholt, A. (2011), "Conveying directional gaze cues to support remote participation in hybrid meetings", Toward Autonomous, Adaptive, and Context-Aware Multimodal Interfaces. Theoretical and Practical Issues, Springer, Berlin, Heidelberg, pp. 412-428.

Vandemeulebroucke, T., de Casterlé, B.D. and Gastmans, C. (2018), "How do older adults experience and perceive socially assistive robots in aged care: a systematic review of qualitative evidence", Aging and Mental Health, Vol. 22 No. 2, pp. 149-167.

Wang, R.H., Sudhama, A., Begum, M., Huq, R. and Mihailidis, A. (2017), "Robots to assist daily activities: views of older adults with Alzheimer's disease and their caregivers", International Psychogeriatrics, Vol. 29 No. 1, pp. 67-79.

Winstead, V., Anderson, W.A., Yost, E.A., Cotten, S.R., Warr, A. and Berkowsky, R.W. (2013), "You can teach an old dog new tricks: a qualitative analysis of how residents of senior living communities may use the web to overcome spatial and social barriers", Journal of Applied Gerontology, Vol. 32 No. 5, pp. 540-560. 
Wirth, W., Hartmann, T., Böcking, S., Vorderer, P., Klimmt, C., Schramm, H., Saari, T., Laarni, J., Ravaja, N., Gouveia, F.R. and Biocca, F. (2007), "A process model of the formation of spatial presence experiences”, Media Psychology, Vol. 9 No. 3, pp. 493-525.

Yates, L.A. and Orrell, M. (2016), "Cognitive leisure activities and future risk of cognitive impairment and dementia: systematic review and meta-analysis".

Zhao, E., Tranovich, M.J. and Wright, V.J. (2014), "The role of mobility as a protective factor of cognitive functioning in aging adults: a review", Sports Health: A Multidisciplinary Approach, Vol. 6 No. 1, pp. 63-69.

\section{Further reading}

Galani, A. and Chalmers, M. (2010), "Empowering the remote visitor: supporting social museum experiences among local and remote visitors", Museums in the Digital Age, pp. 159-169.

Kuflik, T., Stock, O., Zancanaro, M., Gorfinkel, A., Jbara, S., Kats, S. and Kashtan, N. (2011), “A visitor's guide in an active museum: presentations, communications, and reflection", Journal on Computing and Cultural Heritage (Heritage), Vol. 3 No. 3, pp. 1-25.

Riva, G., Davide, F. and IJsselsteijn, W.A. (2003), "Being there: the experience of presence in mediated environments", Being There: Concepts, Effects and Measurement of User Presence in Synthetic Environments, Vol. 5.

Selwyn, N. (2004), "The information aged: a qualitative study of older adults' use of information and communications technology", Journal of Aging Studies, Vol. 18 No. 4, pp. 369-384.

Tsai, T.C., Hsu, Y.L., Ma, A.I., King, T. and Wu, C.H. (2007), "Developing a telepresence robot for interpersonal communication with the elderly in a home environment", Telemedicine and $e$ Health, Vol. 13 No. 4, pp. 407-424.

White, H., McConnell, E., Clipp, E., Bynum, L., Teague, C., Navas, L., Craven, S. and Halbrecht, H. (1999), "Surfing the net in later life: a review of the literature and pilot study of computer use and quality of life", Journal of Applied Gerontology, Vol. 18 No. 3, pp. 358-378.

Wright, K. (2000), "Computer-mediated social support, older adults, and coping", Journal of Communication, Vol. 50 No. 3, pp. 100-118.

\section{Corresponding author}

Galena Pisoni can be contacted at: galena.pisoni@unitn.it

For instructions on how to order reprints of this article, please visit our website: 